\title{
Redevelopment after the Abruzzo Event
}

\author{
Margherita Mori
}

Department of Systems and Institutions for the Economy, University of L'Aquila, L'Aquila, 67100, Italy

\begin{abstract}
Natural disasters raise quite a number of interdisciplinary issues concerning regional growth and local development, as well as public finance and sustainability, to mention just a few of them: they deserve special attention in our globalized world, given the expectation of a growing impact of climate-related disasters; interesting lessons can be learned from the events under investigation and can be successfully shared as a payback to those who helped upon their occurrence. A case in point has to do with the devastating earthquake - known as the Abruzzo event - which occurred in L'Aquila and its environs on April 6, 2009 and revived the debate on recovery problems to be faced under similar circumstances. Due to the huge amount of money needed for redevelopment purposes, financial management plays a key role and useful insights can be gained by exploring the process of financial innovation, encompassing cat bonds and micro-finance: micro-credit might be resorted to even within the framework of new financial engineering instruments, such as Urban Development Funds; they include some initiatives recently promoted by the European Investment Bank and the European Commission (such as JESSICA, JEREMIE, and JASMINE), to be properly considered in sight of rebuilding L'Aquila and its surrounding boroughs.
\end{abstract}

Keywords Cat Bonds, Financial Innovation, JASMINE, JEREMIE, JESSICA, Micro-finance, Natural Disasters, Urban Development Funds

\section{Introduction}

Cross-cultural issues concerning regional economic growth and local development, as well as public finance and sustainability, to mention only a few of them, call for special attention in the aftermath of a natural disaster, as well as after a man made one, such as an act of terrorism. If this is the unfortunate case, extensive damage may be caused to the - both economic and natural - environment, to properties, and to wildlife, apart from the high number of people who may be killed or injured as a result; a bottleneck in human evolution may be eventually created and nobody is justified to feel safe, because natural disasters may occur almost everywhere. In order to take adequate action, an interdisciplinary range of academic and professional skills is required, including engineers, geoscientists, architects, planners, public officials, and social scientists; researchers, practitioners, educators, government officials, and building code regulators are assumed to cooperate [1] in sight of developing and carrying out both ex-ante and ex-post strategies.

No surprise that disaster management stands as a new discipline aimed at bridging the gap between theory and practice, so as to prevent natural disasters in the first place, with financial management spearheading the priority list.

* Corresponding author:

margherita.mori@univaq.it (Margherita Mori)

Published online at http://journal.sapub.org/mm

Copyright (C) 2011 Scientific \& Academic Publishing. All Rights Reserved
Needless to say, a huge amount of money is involved in redeveloping an impacted area so as to restore its economic environment, to accelerate its business recovery, to recreate its vital energies as quickly as possible, and eventually to carry out specific improvement projects as a sort of compensation for the - both personal and economic - losses suffered by affected people, which leads to emphasize the role played by finance. Much consideration has to be paid to public finance, provided that the private sector alone could hardly bear all the costs associated with natural disasters and, by the way, this is unlikely to be the only impacted sector. While valuable opportunities stem from public-private partnership models, not only in a disaster management framework, the recovery process is likely to take advantage to a remarkable extent of the strategic tools that can be devised by exploring the financial system and each of its pillars: namely financial services, institutions, and market segments [2].

The ongoing process of financial innovation has proven useful to satisfy specific needs dealing with finance, as they emerged from time to time, and eventually to stimulate them, to the benefit of both suppliers and consumers of financial services for the last decades: the wide exposure to natural disasters and their potential negative impact may encourage to exploit the opportunities stemming from this process, which is far from exhausted despite not being a recent phenomenon anymore and includes new financial engineering instruments; they can be assumed to help in an attempt at taking precautionary measures and even at fostering preparedness as a primary goal to be reached by all 
those who are exposed to the risks implied by natural disasters. Based upon these assumptions, precious lessons can be learned from the solutions actually adopted to solve real-world problems, such as the ones that dramatically surfaced in the Abruzzo region, in Central Italy, where a devastating earthquake occurred on April 6, 2009.

\section{Objectives}

The Abruzzo event - as this natural disaster is currently referred to [3] - affected more than 50 municipalities in the vicinity of L'Aquila, which is the capital of this region and a city of about 73,000 people: they are now scattered all around the region itself and even elsewhere; thousands of them have definitely moved away and will never get back to the impacted area. Over there, this earthquake caused more than 300 deaths, injured about 1,600 people, destroyed or damaged 10,000-15,000 buildings as well as a large part of essential infrastructure networks, resulted in the temporary evacuation of as many as 80,000 inhabitants in the whole area, and left more than 24,000 homeless: despite all the efforts that have been undertaken since then, most of the city centre remains cordoned off and there are no alternative sites in the outskirts, so that the resumption of commercial activity in L'Aquila is still very limited [4]; according to negative though realistic - estimates, it will take decades to overcome the disaster management problems that still have to be solved in that region. Yet, they were originated in a few seconds and consequences could have been even more pervasive if this event had not occurred at night, right after a week end and before the Easter break.

Many of the cultural sites in the impacted area were badly damaged or destroyed, including Romanesque churches, palazzi, and other monuments dating from the Middle Ages and Renaissance: the historic centers of villages in the Aterno River valley Southwest of L'Aquila - Onna, Paganica, and Castelnuovo among others - were essentially obliterated as a result of extensive damage, beyond repair; with the economic framework being severely affected by such a disruptive earthquake, not even tourism can help as a strategic asset, since L'Aquila and its environs have lost most of their attractiveness as a consequence of the shocks, going on for months, even before the "big one". Societal impacts have contributed to worsen the situation, so that the recovery process does not consist of simply re-establishing the physical environment.

Looking at this area almost three years later may provide valuable insights that can speed up the fulfillment of major objectives, such as identifying preventive measures and exit strategies: both of them are likely to prove extremely helpful to cope with such unwanted events as natural disasters all around our global village; further goals include the search for new strategic tools designed to redevelop an impacted area. To this end, the Abruzzo event looks like a case study to be taken advantage of, due to the useful lessons that can be learned from what happened over there; while different strategies may be adopted in different areas that are exposed to natural disasters or that have been affected by one of them, shared troubles are likely to benefit to a considerable extent from common solutions and joint projects.

\section{Methods}

As far as the methodological issues, in order to achieve the best results the local perspective has to be properly combined with the global one, according to the more and more widely accepted glocal approach; additional efforts should be undertaken to bridge the gap between theory and practice, as well as to satisfy the cooperation-competition equilibrium condition as a requirement, not just an option. In an attempt at reaching these goals, it seems convenient to give priority to a case-by-case approach.

This is why the following considerations have been developed by focusing on the various problems pervading L'Aquila and its surrounding boroughs after April 6, 2009 as well as on the most viable solutions adopted over there since then, not to mention the set of preventive measures taken, just in case another shock occurs over there. Special comments have to do with University-related issues, certainly not to be overlooked, as it can be argued by monitoring the impact that natural disasters caused elsewhere, such as in Louisiana (U.S.A.) after Hurricane Katrina [5], back in 2005: as a matter of fact, L'Aquila hosts a multi-campus and multi-disciplinary University responding to the educational needs of a quite large community of students; they amounted to about 25,000 and accounted for almost one third of the people living in the city before the earthquake.

Like it has been experienced afterwards, reconstruction and redevelopment after a natural disaster are very hard, yet fundamental tasks if a University is located in the affected area: it is not just a matter of re-opening the classrooms and getting a few research projects re-started: activities to be performed amount to a long list, as it had to be realized after a post-earthquake survey of damage on campus at the University of L'Aquila; it was only the starting point of a demanding process, including measures aimed at making up for losses in research labs and librarian resources. Therefore, faculty members, as well as practitioners, are in a position to help their own environment revive and to share their direct experience, if allowed to; they may even contribute to an international network which is likely to take advantage of their advice, based upon their personal involvement in a natural disaster, such as the Abruzzo event.

\section{Results}

The recourse to these methods, in sight of pursuing the goals that have been proposed, provides a set of interesting results. They include valuable lessons learned worldwide, which tend to highlight the role to be played by a positive attitude towards preparedness and lead to stress the relevance 
of both social and personal identity while coping with natural disasters; in addition, useful insights can be gained into terror management, though attention should be ultimately focused on disaster relief and its cross-cultural implications, in order to speed up the recovery process.

\subsection{Lessons Learned Worldwide}

What fuels feelings of pessimism is that a natural disaster - just like a man made disaster, such as an act of terrorism could affect almost anybody anywhere, in a pervasive way: consequences may range from extensive damage to the business scenario, natural environment, wildlife, and real estate to the high number of persons who either die or report casualties, up to the creation of a bottleneck in human evolution. At the same time, important challenges are posed in terms of reconstruction efforts aimed at fostering recovery and growth, as it can be argued by thinking of the Abruzzo event, as well as of floods, avalanches, volcanic eruptions, hurricanes, cyclonic storms, heat waves, wildfires, tornadoes, and other natural disasters.

Due to the wide exposure to catastrophic risks and their potentially unlimited negative impact, a strong awareness is required so as to both prevent natural disasters and eventually try to limit their effects through preparedness. According to lessons learned in L'Aquila and in other impacted areas worldwide, action to be taken before a natural disaster should be coupled with exit strategies to be planned and carried out without delay afterwards: for example, it has to be stressed the need for enterprises to rely on disaster recovery planning; to this end, there is no choice but to face disaster management issues by applying theory to practice, which is especially tough when it comes to solve the economic, financial, business, managerial, and social problems associated with redeveloping an affected area.

Drawing upon experience may prove helpful: from this point of view, it sounds consoling that similar problems have been confronted with in different places, in spite of their specific features and of the possibility to choose from different models for recovery purposes; therefore cooperation can speed up the redevelopment process, thanks to - among other factors - interdisciplinary projects to be shared by those who have had direct experience of natural disasters. Indeed, affected scholars and practitioners alike are in the best position to upgrade knowledge and expertise concerning disaster management, including the creation of an office of emergency preparedness and the adoption of other measures that may allow to reap the benefits of a disaster-resistant University.

\subsection{The Role of Preparedness}

For sure, much can be done in order to minimize the potential impact of natural disasters through the spread of a "culture of preparedness" [6], which is essential too in order to cope with the expectation of a growing impact of climate-related disasters on people [7]: it seems as if though the frequency of the events under scrutiny is increasing all around the world, with new dramatic stories that keep on emerging every day about earthquakes, hurricanes, tsunamis, and forest fires ravaging some part of our global village; by the way, for the disaster preparedness goals to be fulfilled, a considerable involvement is required. The role performed by local enterprises in an attempt at creating new sources of development in the aftermath of a natural disaster leads to emphasize the need to adopt a continuity planning approach for disaster-readiness, which encompasses crucial tasks designed to maintain or quickly resume the most mission-critical functions.

The continuity plan itself can be represented as the core of the whole planning exercise referred to information technology infrastructure and planning for non-IT related aspects, such as key personnel, facilities, crisis communication, and reputation protection: as a matter of fact, plans for resumption of applications, data, hardware, communication (such as networking), and other IT infrastructure have gained growing importance due to the transition to an around-the-clock economy. Unfortunately, smaller companies are reportedly more exposed to failures, no matter how much financial support they may receive following a natural disaster, because of their lower level of competencies and resources, and the overall weight of these firms in the business environment is unlikely to help the recovery process to result in success stories.

Within this framework, the objective of retail redevelopment and growth stands as a priority, closely connected with the aim of restoring confidence. Apart from economic and financial drawbacks, retailers are likely to suffer major structural damage, not to mention the difficulty of trying to sort out personal losses and also have to cope with changes in consumer motivations in the aftermath of a natural disaster: after a tragedy, survivors can be expected to consciously seek products that are supposed to heal their wounds; once basic needs have been satisfied, people in a disaster recovery area may show a remarkable attitude towards social and personal identity.

\subsection{Social and Personal Identity}

On one side, it seems natural to express solidarity with the community and its redevelopment efforts; on the other side, an unprecedented sale of self-shooting products may be justified by a massive attempt at overcoming trauma and hence at pursuing cherished possessions. As far as social identity, it can be referred to the sentiment of being a member of a social category, provided that identification with an area (a city, a region or even a country) is stronger after it has been impacted by a natural disaster.

For instance, cloths and jewels reminding of that area tend to be publically displayed and, as such, can reflect a sense of being solid for the affected people better than other products. By contrast, personal identity relates to one's private sense of self, which leads to pay unprecedented attention to home items (and, in more general terms, to products usually enjoyed at home, such as art works, books, and periodicals), as 
being able to offer intrinsic identity satisfaction: it is interesting that a graphic novel about the storm was created in the aftermath of Hurricane Katrina in New Orleans (LA, U.S.A.) and that found objects were recycled to make art works over there; anecdotal trends include an unexpected increase in sales for Katrina themed items.

This growth can be at least partially explained by observing that "patriotic lure" helped to encourage tourists to visit the disaster area, so as to support the tourist industry as a strategic asset. All in all, consumers are likely to be very fragile after a natural disaster; as such, their purchasing attitude is more oriented than before it towards both social and personal identity markers, which leads to suggest retail therapy as a possible way to minimize the negative impact on the disaster area and to bolster the morale of its people.

\subsection{Terror Management}

At the same time, affected consumers seek community connection and consequently are more oriented to buy from locals in order to reinforce identity in purchasing behavior. In turn, for their strategies to prove more effective, retailers should communicate their connection to the impacted area: in a few words, managerial implications also reinforce the argument that local support has to be showed, while insights from terror management lend themselves to be usefully combined with those from consumer theories.

Some both theoretical and practical conclusions can be easily reached. It is meaningful that a relevant source of terror is identified with uncertainty of time and place of one's death; following a natural disaster, people actively thoughnot necessarily with full awareness - seek ways to reaffirm their shaken sense of self; attitudes that are supposed to reinforce their self-esteem and upgrade their world-views can be intensified as a result of facing life or death situations; cultural wipe-out makes it hard to reconstruct identity even though the spirit lives on; maintaining culture enhances self-esteem and hence fuels the drive to undertake recovery efforts.

To make the situation even more challenging in the business arena, appropriate plans differ from an enterprise to another, depending on such variables as the type of business, the processes involved, and the level of security needed. In general terms, the suggested pathway consists of quite a number of steps, including the following: participation in an in-take interview which helps to get a better understanding of strengths and weaknesses and to identify the most relevant areas to focus the disaster recovery planning process on; implementation of a continuity of operations plan using specific elements, as appropriate; preparing staff for emergencies; institutionalization of an incident command system; adoption of measures to mitigate potential damage, for example by bracing and anchoring building contents; cooperation with the broader network of preparedness in the area.

\subsection{Disaster Relief}

To firms, as well as to households, preparing for an eventual need to recover after a natural disaster is a very exacting task that has to be performed by taking advantage of a full range of information and background. The foresight to recognize the value of business continuity planning is a must, not just $a$ plus: the resulting plan should be coupled with specific precautionary measures designed to prevent disasters in the first place and eventually to minimize their foreseeable consequences, for instance by making recourse to uninterruptible power supply. In a few words, disaster management can be described as being built upon the $7 P_{S}$ represented by People, Program, Processes, Performance, Providers, Premises, and Profile.

While their relevance is unquestionable, there can be no doubt that disaster relief implies much more than facing these managerial implications, because of the wide array of counseling services needed as valuable assets: they range from management and technology transfer assistance to entrepreneurial training, from business incubation to access to capital. Overall, the main goal is to both save and create jobs, which implies huge efforts for the economic environment to be revived, redevelopment to be fostered, entrepreneurship to be increased, and finally growth to be promoted, with sustainability issues certainly not to be neglected.

A key role should be played by disaster business counseling, encompassing business planning, loan applications, and training workshops; as far as management assistance, four main areas call for attention, namely general management, financial management, operations management, and technology management. To make a long story short, disaster recovery is a burdensome and time consuming process which requires the assistance of a network of professionals in a variety of fields, though the huge amount of money involved leads to consider financial skills of foremost importance.

\section{Discussions}

The results attained by looking at several lessons learned worldwide from natural disasters lead to discuss their financial implications, given the role that finance plays in order to cope with these unwanted events. One of the major sources of concern has to do with funding the recovery process: to this end, financial innovation can prove fruitful, as shown by the recourse ethical finance, micro-finance, real estate funds, and innovative tools such as Urban Development Funds; special attention has to be paid to some initiatives recently promoted by the European Investment Bank and the European Commission, including JESSICA (Joint European Support for Sustainable Investment in City Areas), JEREMIE (Joint European Resources for Micro to Medium Enterprises), and JASMINE (Joint Action to Support Micro-finance Institutions in Europe). While these financial services may help to carry out the recovery process and hence fall within the category of the ex-post strategies, preventive measures, encompassing cat bonds, seem to be even more relevant in sight of supporting the adoption of a culture 
of preparedness.

\subsection{Financial Implications}

It is undisputable that financial skills allow to exploit the potential of all available opportunities and to choose the most suitable to support the redevelopment process, including those labeled as not-for-profit finance: for example, in order to conveniently evaluate access to both traditional and innovative financial instruments, bank financing should be carefully compared to angel investing, private equity, and venture capital, as well as to micro-finance and particularly to micro-credit, depending on the specific needs to be satisfied. Further options can be devised by taking advantage of the process of financial innovation, which is far from exhausted.

Therefore, making recourse to the three pillars that the financial system is built upon (financial services, institutions, and market segments) looks like a pre-condition to accelerate the rebirth of affected areas and to convert their recovery into a long-term, smart and sustainable growth, after a natural disaster such as the Abruzzo event. Actually, new strategic tools come into being daily in the financial arena, due to significant efforts undertaken to modernize it on a continuous: the creative energies that continue to pervade this process, in finance as well as in other fields, could help to cope with the long list of challenges posed by natural disasters, with crucial investment areas being identified with healthcare and economic development, as well as urban renewal, not to mention the need to enhance public assets and infrastructure.

In particular, activities to be carried out in an impacted area encompass safeguarding adjacent neighborhoods and establishing housing opportunity zones to incentive homeownership. In sight of these goals, a public-private economic development partnership may be eventually resorted to, provided that this arrangement allows to put together the benefits stemming from Government resources, private sector investment, effective laws and policies, economic research and expertise; in addition, the recovery process should be promoted by supporting existing firms with the highest chances to survive and by fostering the development of new enterprises, which could be expected to stimulate business survival, formation, and growth.

\subsection{Funding the Recovery Process}

As far as funding this process, banking foundations could be primarily interested in contributing to it as a part of their mission oriented towards the communities that they are respectively linked to. Looking at the financial system in a broader perspective, local banks should result most actively involved in disaster preparedness and recovery improvement programs, because these institutions are at risk more than the large ones, in case a natural disaster occurs where their branches are located; yet, the affiliation to a financial or banking group is likely to preserve the banks in a disaster area. This holds true especially for the smaller ones that could hardly cope by themselves with the devastating consequences of a natural disaster, provided that upon its occurrence the economic environment might worsen sharply and default rates grow accordingly.

To further deteriorate the picture, the current value of assets pledged against the repayment of mortgage loans before one of the events under scrutiny may drop afterwards to an unexpectedly low level, as it can be said of damaged real estate. Even banks may be physically damaged or destroyed following such a natural disaster: their back-up facilities are likely to provide much relief, if relevant data can be resumed, and relying on insurance policies can prove helpful to cover at least some of the losses suffered; however, some types of risks that are normally considered of minor importance compared to credit risk, such as operating and legal risks, may fully display their potentially negative effects and gain momentum as a part of the global risk management strategy.

A closer look at the financial side of redevelopment strategies reveals that remarkable benefits can be reaped by carrying out a number of activities aimed at fund-raising, so as to stimulate adequate financial support, and specific programs could be undertaken to this end. Precious opportunities may be offered also by enterprises and citizens spontaneously acting as donors, as well as by foundations of any kind (not only banking foundations), and being able to take advantage of their proposals may prove a challenge by itself, under the severe conditions prevailing in an affected area: each goal has to be defined in a detailed way; the related projects need to be managed professionally; expenses have to be carefully accounted for to the donors as well as their stakeholders as a whole.

\subsection{Ethical Finance}

Sometimes grants are conditioned upon their use to carry out a single initiative, possibly tied to the donor's image, thus generating the need to cope with specific issues. This is what happened with a donation to the University of L'Aquila by Parmalat S.p.A., a global player active in milk and diary products, as well as fruit-based beverages: a generous contribution was announced right after the Abruzzo event, with one third of the money donated by the company's employees.

This grant was intended to be used for implementing a unique project and, after a joint evaluation of several options, it was decided to create a micro-biological laboratory for both research and teaching purposes, tailored to the mission and field of interest of the contributing firm; further activities could be eventually undertaken in cooperation with local agricultural firms so as to support their recovery. Despite the difficulty of finding adequate premises, due to the pervasiveness of damage on campus, the Parmalat Lab was opened on July 15, 2010 and a scholarship was additionally offered to cover its operating expenses during the first year.

While this success story leads to emphasize the role played by ethical finance and, in more general terms, by not-for-profit finance, it is also worth mentioning the crowd 
funding approach, that has long precedents in the sphere of charity and is receiving increased attention. One of the reason is that social media, online communities, and micro-payment technology make it straightforward to engage in and secure donations at a very low cost: according to an emerging view, crowd funding - also known as crowd sourced capital or crowd financing - is the name of a collective cooperation, attention, and trust by people who network and pool their money together, usually via the Internet, in order to support efforts initiated by other people as well as by organizations. Actually, disaster relief is one of the main purposes that crowd funding occurs for.

\subsection{Micro-credit}

Furthermore, the high number of micro-, small-, and medium-sized enterprises located in L'Aquila - as well as in other impacted areas - leads to pay unprecedented attention to micro-finance as a strategic way out after a natural disaster, for the local community and business environment to recover. In particular, micro-credit allows to borrow a smaller amount of money than the loan size usually offered by commercial banks, which may help companies to survive and hopefully grow, despite being denied access to traditional banking and related services, mainly due to the collateral aspect of loan requests: from this standpoint, it appears that banks have been more and more concerned with risk capital and capital requirements, as the reform of the original 1988 Basel Accord culminated in what bank supervisors refer to as Basel II [8]; the call for Basel III [9] should further enhance the role of risk assessment and measurement, which fuels fears of pessimism among borrowers.

The troublesome conditions that the recent financial crisis has brought about and that include the tightening of credit standards, above all by the largest banking groups [10], have added to the difficulties that surfaced after the earthquake in the Abruzzo region and especially in the province of L'Aquila. According to a common explanation, financial institutions must incur substantial costs to manage each loan, including the expensive assessment of the implied credit risk, and these costs discourage them from lending a limited amount of money; in other words, a break-even point can be devised (in terms of loan size), below which banks would not find it convenient to fall.

By contrast, these loans are usually appreciated by people - including consumers and self-employed individuals, as well as those belonging to the institutional sector made up of producer households - who own few assets to be secured by financial institutions as a borrowing base. Focusing on real estate drawn upon as a collateral, it must be recognized that financial institutions may end up with having no recourse against a defaulting borrower when her/his properties are no longer marketable, due to the negative consequences of a disaster: in these cases, it is more likely that outstanding loans will be quickly called by creditors than further lending will be granted to the same customers, who may desperately need to borrow so as to get their business restarted; within this discouraging framework, the success of Grameen Bank now serving millions of women in Bangladesh should inspire confidence.

\subsection{Tradition and Innovation}

Apart from micro-lending to enterprises as a recovery strategy, thanks to a loan consisting of a limited amount of money households can support spending in an impacted area, with a special emphasis to be put on family-owned small companies that represent a unique category of firms for mixing up the characteristics of both enterprises and households [11]. Nobel prize Muhammad Yunus greatly contributed to bring the kinds of livelihood opportunities and risk management tools that financial services provide to the doorsteps of poor people through micro-credit; similar criteria may be usefully adopted in an attempt at satisfying the basic financial needs generated by redeveloping an area after a natural disaster, as an alternative to both traditional lending principles and illegal practices, such as usury.

However, the advantages associated with micro-credit cannot be thoroughly grasped if its description is conditioned upon its smaller size than traditional bank loans. Indeed, non banking financial institutions have grown up and multiplied by specializing in this market segment and much of their success is due to the development of innovative distribution channels: new ways of delivering loans fall within the concept of financial innovation, regardless of their amount, since they imply a change in the place factor of the marketing mix; according to conventional studies, this strategic tool also includes such variables as product, promotion, and price to make up the 4 Ps.

It is also noticeable that micro-credit consists of a sub-set of micro-finance, encompassing micro-lease and micro-equity financing, as well as micro-insurance policies and even micro-deposits; all these financial instruments are likely to prove beneficial in the aftermath of a natural disaster, though their usefulness may possibly be taken advantage of well beyond this framework. Since the financial sphere of the economy is assumed to more and more efficiently support the real one, even too creative solutions have been devised in an attempt at sustaining company liabilities, which has made non-banking services and institutions proliferate, including those involved in micro-lending, while banks keep on performing vital functions.

\subsection{Case Studies}

Again, the Abruzzo event can be pointed at as a source of interesting ideas. One of them has to do with the project known as Microcredit for Abruzzo, that was developed by Consorzio Etimos and presented on July 22, 2010: based upon micro-finance as a way-out strategy, this programme has been arranged so as to take advantage of the donations managed by the Italian Department of Civil Protection and to profit by the cooperation offered by several partners, including a number of local banks; they are mostly mutual banks representing a category of banking intermediaries that 
traditionally have provided financial services for the agribusiness and hence small agricultural firms in the area may be attracted by them.

Additional lessons learned from the Abruzzo event allow to stress the relevant role that can be played by Universities, especially if they are located in an impacted area; they may even share cooperative efforts, such as the ones jointly undertaken by the University of L'Aquila and Louisiana State University and Agricultural \& Mechanical College (LSU) in Baton Rouge (LA, U.S.A.) on redevelopment after a natural disaster, a program sponsored by the US State Department following the G-8 Summit that was relocated to L'Aquila right after the Abruzzo event. To make knowledge and expertise spread, as the academic mission implies, special attention can be drawn to the mobile classroom that has been set up by the Louisiana Business \& Technology Center, an integral part of the E. J. Ourso College of Business at LSU: it is a converted semi-trailer that can be utilized also as a 30-seat business incubator on wheels to reach the unserved communities in rural Louisiana and encourage to seek further assistance; thanks to this entrepreneurial program, extensive business counseling has been provided, first of all to firms in some of the areas most severely impacted by Katrina, which originated a widespread need to educate on various recovery programs, loans, grants, and tax incentives.

The ambitious results attained over there do not only give satisfaction for international interest, in line with the more and more widely accepted glocal perspective, but also sound like an invitation to replicate them by adopting this case study as a contribution to foster long term, sustainable growth in an impacted area: for its recovery to be pursued, money should fully display its potential as an input, as important as any other one; at the same time, innovative opportunities can be taken in the financial arena, that are likely to speed up the flight to quality in the business environment after a natural disaster. If this is not easy, what may prove even harder is to make aware of them the small - and even micro - enterprises that prevail in the real (versus the financial) sphere of the economy, so as to upgrade their financial management and eventually gain greater access to finance, including micro-credit.

\subsection{Cat Bonds}

While micro-finance has just started to be considered as a strategic tool that may possibly support the recovery process in L'Aquila, as elsewhere, alternative options can be found out by taking advantage of the process of financial innovation [12]. A case in point has to do with catastrophe (briefly, cat) bonds, designed to manage the risk associated with natural disasters by transferring it to investors, who may finally bear the resulting losses; if cat bonds are still considered as being in their infancy, their increased popularity right after a tragedy such as Katrina emphasizes the role that they can play in our new, climate-changed world.

Cat bonds are often structured as floating rate debentures whose principal is lost if specific trigger conditions are met: if triggered, the principal is paid to the sponsor; the triggers are linked to major natural disasters and this is why the notion of catastrophe risks became prominent in the aftermath of Hurricane Andrew, back in 1992. Insurers and reinsurers typically use these bonds as an alternative to traditional catastrophe reinsurance and retrocession coverage, when these forms of risk transfer are too costly, require the assumption of too much counterparty credit risk or don't align with broader risk-management thresholds or objectives.

Sponsors also include corporations and government agencies that aim at passing catastrophe risk along, with investment banks and other financial institutions acting as dealers being increasingly involved in the issuance of these bonds. On the demand side, market participants tend to be identified with institutional investors such as specialized cat bond funds, hedge funds, money managers, life insurers, reinsurers, and pension funds, provided that individual investors usually buy these securities through specialized funds; investing in cat bonds may look attractive because their yield is largely uncorrelated with the return on other investments in fixed income assets or in equities.

\subsection{Ex-ante Versus Ex-post Strategies}

No question that these still relatively new financial products help investors to diversify their portfolios while carrying out an asset allocation strategy; furthermore, they generally pay higher interest rates (in terms of spreads over traditional funding rates) than comparable corporate instruments, as long as they are not triggered. Looking at the financial arena as a huge laboratory, with both real and virtual implications, it is revealing that some of the most recent cat bond issues have been launched to pass along US hurricane risk, as well as to protect against Japanese earthquake and European windstorm risks, which provides an immediate proof of the widely felt need not to remain exposed to them.

Cat bonds share some similarities with weather derivatives: they started to be traded in the United States at the end of the nineties, in an attempt at figuring out how to manage and, particularly, hedge - weather risks; direct exposure to them can involve as many as one million firms estimated in agriculture, forestry, and fishing in Italy [13]. Apart from their large number, what makes hedging encouraging is that these market segments are weather sensible and hence should not result unfamiliar with a disaster management framework, given the expectation of a growing impact of climate-related disasters.

Both cat bonds and weather derivatives fall within the category of the strategic tools to choose from while adopting preventive measures. Ex-post strategies too can be developed by resorting to financial innovation and particularly to new financial instruments, including social lending: also known as person-to-person lending and peer-to-peer lending, it involves funds provided directly between individuals (peers) without the intermediation - or even the participation - of a traditional financial institution; an enabling technology has been the Internet, which allowed to introduce two primary 
variations, namely an online marketplace model and a family and friends model.

\subsection{Real Estate Funds}

On a less innovative side, it is worth mentioning the opportunity to rely on real estate funds in an effort to recover after a natural disaster, such as the Abruzzo event. In fact, they are created by a group of real estate professionals or experts in order to manage property and real estate for investors: these funds share some features with mutual funds, since they work towards a common cause, which entails maximizing returns for the investor; in addition, real estate funds can be simply described as implying the same risks that are associated with equity and debt mutual funds, including volatility, and as entailing a similar set of charges, such as fund management fees, brokerage fees, and administration fees.

Based on their characteristics, real estate funds stand as potential actors in sight of redeveloping an impacted area: with thousands of buildings being either destroyed or badly damaged as a result of a natural disaster, there is wide room for investing in real estate by financial institutions specializing in purchasing, repairing and/or rebuilding as appropriate, in order to rent or sell the property afterwards; the other side of the coin features owners willing to sell their damaged property for an acceptable price, while to individual investors these funds are appealing as a way to pursue the desired allocation between financial and real assets without directly owning any property, which also allows to diversify away a portfolio to an otherwise impossible extent, as far as holding real estate as an asset class. The regulatory framework applicable to real estate funds under Italian law makes their regime complex, which by the way should not discourage from further exploring their potential in L'Aquila and its surrounding boroughs, to the benefit of both investors and owners willing to get rid of their damaged property without loosing too much money.

The efforts undertaken in this market segment have proven rewarding, as shown by the unprecedented solutions that have been adopted by real estate funds in the United States, where their industry has evolved in to a concept called the Real Estate Investment Trust (or REIT). To summarize, it can be described as a publicly listed entity, which basically passes on at least 90 per cent of its profits to investors: REITs buy, develop, and sell properties in order to finally share profits with investors, acting as unitholders, from any capital appreciation on the sale of property; apart from sales, real estate funds make money from rentals on property owned by them.

\subsection{Urban Development Funds}

Real estate funds also share some similarities with urban development funds (UDFs), recently promoted in Europe by the European Investment Bank (EIB). UDFs can be still represented as new financial engineering instruments aimed at supporting investment in sustainable urban development; as such, they are expected to make up an emerging segment of the investment fund market populated with investment vehicles whose specialization deals with identifying - and investing in - sustainable city assets and supporting urban transformation operators capable of achieving sustainable urban development outcomes.

Towards this objective, some of the features of the existing types of funds (such as real estate and ethical funds) can be successfully combined into new organizational structures relying on specific governance modes, professional skills, analytical and networking capabilities. While the market segment under scrutiny has not been given much life yet, it can be anticipated that different forms may characterize UDFs in each European country and region where they are eventually created: in fact, urban development processes under way in Europe widely differ from one another; discrepancies are also evident among their medium- and long-term impacts on the demand for urban assets and services, as well as on their respective investment requirements.

According to the state of the art and current thinking on UDFs, it is still prominent the need to provide them, as investors in sustainable urban development, with a better understanding of the risks and opportunities associated with investing in European cities over an all-but-short time span: for this need to be satisfied as quickly as desired, a key factor has to do with the ability to combine research capabilities, experience, and data resources; one further step implies the recourse to both organizational and operational templates for UDFs, encompassing their legal structures, performance principles, and criteria, as well as methods and benchmarks, for asset portfolios to be correctly assessed and efficiently managed. All in all, UDFs may be usefully resorted to in order to stimulate the redevelopment of areas affected by a natural disaster, such as those impacted in the L'Aquila province, so as to ensure that recovery meets the criteria of a sustainable growth.

\subsection{The JESSICA Initiative}

The support recently offered by the EIB to UDFs acts as a stimulus to analyze similar programs sponsored elsewhere, and particularly in the United States, in order to share know how and good practices. Cases abound, mainly featuring the provision of loans and equity to fund real estate development in the nation's most disadvantaged communities; to remain in Louisiana, an interesting project was designed to renovate the St. Charles Hilton in New Orleans after Katrina and carried out through an arrangement involving adequate financing for the acquisition and rehabilitation of the property, including the move of the mechanicals to the second floor to prevent damage in the case of any future flooding.

What makes the European scenario especially attractive is the opportunity to rely upon the JESSICA initiative, which is expected to foster sustainable investment, growth, and jobs in Europe's urban areas. In a few words, JESSICA is a policy initiative of the European Commission (EC), in cooperation with the Council of Europe Development Bank and the EIB, 
to assist the renewal and transformation of European cities by promoting UDFs: under the JESSICA framework, the managing authorities of Structural Funds programmes can take advantage of outside expertise in order to gain greater access to loan capital for the purposes of promoting urban development, including loans for social housing where appropriate, as it seems to be the case of the recovery process to be carried out after a natural disaster; the ultimate goal can be identified with addressing the scarcity of investment funds, even for public-private partnerships and projects complying with integrated and sustainable urban development criteria.

JESSICA responds to the request by several Member States and the European Parliament (EP) to devote particular consideration to the need for renewal and/or regeneration of certain urban areas [14]; as a result, the possibility has been created under the JESSICA initiative to promote and finance urban development projects using revolving instruments such as bonds, equity, and guarantees as opposed to grants. With urban projects being a good catalyst for local economies, the advantages potentially offered by JESSICA should not be overlooked in redeveloping L'Aquila after the earthquake [15] and the University could still play a key role, since this initiative is part of a line of research undertaken through the EIBURS (European Investment Bank University Research Sponsorship) programme for the 2009-2012 period.

\subsection{The JEREMIE Initiative}

New financial engineering instruments developed in the context of the European cohesion policy also include the JEREMIE initiative, to be eventually resorted to in an impacted area, though a disaster management framework is not necessarily required for the adoption of this strategic tool. It is a joint initiative of the EC and the European Investment Fund with the EIB: the aim is to improve access to finance for medium-, small-, and micro-sized enterprises [16], in particular through the supply of venture capital, loans, guarantees, micro-credit, and other forms of innovative financing; after a phase of careful preparation, this programme is now fully operational [17] and can be expected to provide valuable results.

Against the background of weak growth prospects adversely affecting both public and private balance sheets [18], JEREMIE is likely to help support these enterprises, first casualties of the financial crisis that began in the summer of 2007. Just like JESSICA, JEREMIE was announced in 2005 by the EC, in close cooperation with the EIB Group and is designed to allow managing authorities to use some of their Structural Funds allocations to invest in revolving funds, rather than once-off grant financing; therefore recyclable forms of assistance should be encouraged, while discouraging an exclusive reliance on grants.

Both of these initiatives fall within the category of public-private partnership innovative models that can be conveniently used as a part of the continuing effort to make the cohesion policy more effective. As a matter of fact, national and regional authorities are confronted with growing in- vestment needs while the available public resources become more and more scarce; it is estimated that by the end of 2015 , JEREMIE and JESSICA will build up a lasting funding legacy of European Union (EU) and national public money, to be recycled and reinvested in the long term to the benefit of small and medium enterprises and in the field of urban development all over Europe.

\subsection{The JASMINE Initiative}

More recently, the EC has promoted the JASMINE initiative, which aims to make small loans, or micro-credit, more widely available in Europe, in an effort to satisfy unmet demand [19]. This initiative was launched in 2008 by the EC, the EIB Group and the EP to improve access to finance not only for small businesses, but also for socially excluded people, such as ethnic minorities who want to become self-employed; in line with the Lisbon Strategy for growth and jobs, positive effects may be generated in impacted areas, where the social environment may change all at a sudden, in a dramatic way, as it has been experienced after the Abruzzo event.

While fostering smart, sustainable, and inclusive growth, JASMINE is intended to prove beneficial to social and regional cohesion in the EU. The pilot project is supposed to run from 2009 to 2011, mainly based upon the provision of technical assistance to micro-finance institutions (MFIs), so that they can improve their managerial skills and become higher quality operators; it also provides limited funding to MFIs through resources made available by the EIB and seed capital granted within the framework of a preparatory action requested by the EP.

In particular, technical assistance to MFIs takes the form of an assessment by a specialized rating agency and subsequent training in areas where improvement is needed: this may mean helping MFIs resort to good governance and sound management procedures and demonstrate that every part of their business is reliable; how these institutions manage the risk, how they carry out strategic planning and the completeness of their information systems would be likewise reviewed and improved during training as appropriate, to the benefit of (potential as well as actual) micro-borrowers in the first place. Their continued success and growth depend very much on finance that is relevant to their scale and level of complexity, especially if the target market consists of small enterprises that have been impacted by a natural disaster.

\section{Conclusions}

Of course, public-private partnership innovative models such as JASMINE, JEREMIE, and JESSICA - pave the way for an even wider range of strategic tools that financial management can usefully resort to, when it comes to implement the recovery process in an area that has been affected by a natural disaster. The underlying join for change philosophy may convey benefits that would be out of reach 
on a case by case basis, especially to small firms that could hardly take advantage of existing economies of scale and scope: for instance, the increasing role played by mutual guarantee institutions gives ground for optimism because of the pervasive difficulty of gaining access to small business finance [20], which is likely to prove an even tougher task to impacted firms; the opportunity to issue district bonds acts as a reinforcement, with agriculture standing in a prominent position, due to the growing number of agrifood and rural districts, not only in Italy.

To conclude, redevelopment after a natural disaster is likely to turn out an extremely challenging task, which unfortunately may happen to be performed unexpectedly, almost anywhere in our global village, and may require a long-lasting, high-pressure managerial involvement, apart from the financial resources needed for the business environment to be revived: if it is true that creative energies should be devoted to improve management skills in a way that is right for the times, no one would deny that key in achieving this goal is to act jointly, especially in the aftermath of one of the events under investigation; satisfying the cooperation-competition equilibrium condition is a requirement, not just an option, when coping with them, which implies that realistic solutions have to be crafted, smart practices adopted and capacity to cope with difficulties increased with respect to strategic decision-making. Both the preparation and the response to a natural disaster - as well as to a man made one, such as an act of terrorism - call for leadership roles in the dynamic and complex mission of protecting the homeland and its citizens, in the context of interagency support and cooperation.

No surprise that a number of Colleges and Universities, mainly - but not only - in the United States, have started to specifically widen the range and scope of their degree programmes by including disaster management, with a special emphasis on business continuity training and certification, and to offer the qualifying examination. Anyway, the huge amount of money involved in redeveloping an impacted area leads to focus on finance and on the specific professional skills needed for the best financial solutions to be crafted and adopted: to this end, drawing upon experience is likely to prove useful but the search for new and further ways to fund the recovery process in an impacted area should be actively pursued; within this framework, micro-finance can play a relevant role, provided that micro-credit is designed to support firms as well as households and hence to revive the economic environment, while attenuating the societal impacts generated by a natural disaster, as in the case of the Abruzzo event.

\section{ACKNOWLEDGEMENTS}

This paper is part of a research project that was undertaken in 2009 in cooperation with the Louisiana Business \& Technology Center at the E. J. Ourso College of Business of Louisiana State University and Agricultural \& Mechanical
College in Baton Rouge (LA, U.S.A.), within the framework of the International Visitor Leadership Program on "Redevelopment After a Natural Disaster"; it was sponsored by the US Department of State, Bureau of Educational and Cultural Affairs right after the Abruzzo event. Additional support was granted by the US-Italy Fulbright Commission in Rome (Italy).

Preliminary versions were presented at the Business School of Pforzheim University in Pforzheim (Germany), on May 19, 2010 during the Summer Program in cooperation with the Pennsylvania State University (PA, U.S.A.); at the School of Business of Kajaani University of Applied Sciences in Kajaani (Finland) on September 24, 2010, within the framework of the Erasmus Programme; at the South East European University in Tetovo (Macedonia) on October 21, 2010, in the context of the Tempus Project SATIS (Sustainable Agribusiness and Tourism in the Southern Balkans); at the Cariplo Foundation Conference Center in Milan (Italy) on November 5, 2010 during the workshop on "Financial Inclusion" arranged by Etimos Foundation Onlus; at the Department of Business Studies of the American University of Rome in Rome (Italy) on February 21, 2011; at the Faculty of Business and Communication Studies of the University of Vic in Vic (Spain) on March 16 and 17, 2011 during the "International Business Culture" Course (11 ${ }^{\text {th }}$ Edition), within the framework of the Erasmus Programme; at the Faculty of Agriculture of the University of Szeged in Hódmezövásárhely (Hungary) on May 5, 2011 during the X. Wellmann International Scientific Conference on "Traditions, Innovation, Sustainability"; at the Faculty of Economics and Business of the University of Barcelona (Spain) during the $51^{\text {st }}$ International Congress of the European Regional Science Association (ERSA) on "New Challenges for European Regions and Urban Areas in a Globalised World", held between August 30 and September 3, 2011; at the E. J. Ourso College of Business of the Louisiana State University and Agricultural \& Mechanical College and at the Louisiana Business \& Technology Center in Baton Rouge (LA, U.S.A.) on November 1, 2011.

This is to gratefully acknowledge all those who provided useful insights, valuable comments, precious suggestions and fruitful exchange of views. The opinions expressed are the author's only, who is solely responsible for any errors and omissions.

\section{REFERENCES}

[1] Gruppo di lavoro MS-AQ, Microzonazione sismica per la ricostruzione dell'area aquilana, Regione Abruzzo Dipartimento della Protezione Civile, L'Aquila (Italy), 2010

[2] G. Forestieri, P. Mottura, Il sistema finanziario, Egea, Milan (Italy), 2005, p. 2

[3] Learning from earthquakes, Special earthquake report, Earthquake Engineering Research Institute, Oakland (CA, 


$$
\text { U.S.A.), June } 2009
$$

[4] L'economia dell'Abruzzo, Banca d'Italia, L'Aquila (Italy), June 2011, p. 5

[5] R. Bacher, T. Devlin, LSU in the eye of the storm - A University model for disaster response, Louisiana State University, Baton Rouge (LA, U.S.A.), 2005

[6] R. L. Honorè, Survival - how a culture of preparedness can save you and your family from disasters, Atria Books, New York (NY, U.S.A.), 2009, p. 219

[7] Evaluation of UNDP contribution to prevention and recovery, United Nations Development Programme, United Nations, New York (NY, U.S.A.), Sept. 2011

[8] Basel II: international convergence of capital measurement and capital standards - a revised framework, Bank for International Settlements, Basel Committee on Bank Supervision, Basel (Switzerland), June 2004

[9] Basel III: a global regulatory framework for more resilient banks and banking systems, Bank for International Settlements, Basel Committee on Bank Supervision, Basel (Switzerland), Dec. 2010 (rev. June 2011)

[10] Annual report - ordinary meeting of shareholders - abridged report, Bank of Italy, Rome (Italy), May 31, 2010, p. 126

[11] M. Cucculelli, G. Micucci, Family succession and firm performance: evidence from Italian family firms, Temi di discussione, Bank of Italy, Rome (Italy), 680, June 2008, p. 3
[12] F. S. Mishkin, S. G. Eakins, Financial markets and institutions, Pearson Prentice Hall, Boston (MA, U.S.A.), 2009, p. 452

[13] V. Pacelli, Weather risk management: analisi della domanda e dell'offerta di strumenti finanziari, in S. Dell'Atti (ed.), La finanza a servizio del comparto agroalimentare, Edizioni Scientifiche Italiane, Naples (Italy), 2008, p. 172

[14] Town centre regeneration: how does it work \& what can be achieved?, Scottish Government, Edinburgh (Scotland), Sept. 2011

[15] JESSICA evaluation study in the Abruzzo Region, European Investment Bank, Luxembourg, Dec. 2010

[16] M. Comana, D. Previtali, Il credito e la finanza della micro-impresa: punti di criticità e proposte di miglioramento, Banche e banchieri, July-August 2011, p. 294

[17] Annual report 2010, Activity report, vol. I, European Investment Bank Group, Luxembourg, May 2011, p. 14

[18] Global financial stability report: grappling with crisis legacies, International Monetary Fund, Money and Capital Markets Department, Washington (DC, U.S.A.), Sept. 2011, p. 4

[19] A spotlight on microfinance, European Investment Bank Group, Luxembourg, July 2011

[20] F. Columba, L. Gambacorta, P. E. Mistrulli, Mutual guarantee institutions and small business finance, in Business models in banking: is there a best practice? - Proceedings of the 2009 Banking Conference, Università Bocconi, Milan (Italy), 2010, p. 151 